\title{
Spatiotemporal Changes in Fine Particulate Matter Pollution and the Associated Mortality Burden in China between 2015 and 2016
}

\author{
Luwei Feng ${ }^{1, \dagger}$, Bo Ye ${ }^{2,+}$, Huan Feng ${ }^{2}$, Fu Ren ${ }^{1,3,4}$, Shichun Huang ${ }^{2}$, Xiaotong Zhang ${ }^{2}$, \\ Yunquan Zhang ${ }^{2}$ (D), Qingyun $\mathrm{Du}^{1,3,4,5, *}$ and $\mathrm{Lu} \mathrm{Ma}{ }^{2,6, *}$ \\ 1 School of Resources and Environmental Science, Wuhan University, Wuhan 430079, China; \\ lwfeng@whu.edu.cn (L.F.); renfu@whu.edu.cn (F.R.) \\ 2 Department of Epidemiology and Biostatistics, School of Health Sciences, Wuhan University, Wuhan 430071, \\ China; yeb@whu.edu.cn (B.Y.); 2017203050003@whu.edu.cn (H.F.); 2017283050055@whu.edu.cn (S.H.); \\ XiaotongZhang@whu.edu.cn (X.Z.); Yun-quanZhang@whu.edu.cn (Y.Z.) \\ 3 Key Laboratory of GIS, Ministry of Education, Wuhan University, Wuhan 430079, China \\ 4 Key Laboratory of Digital Mapping and Land Information Application Engineering, National \\ Administration of Surveying, Mapping and Geoinformation, Wuhan University, Wuhan 430079, China \\ 5 Collaborative Innovation Center of Geospatial Technology, Wuhan University, Wuhan 430079, China \\ 6 Global Health Institute, Wuhan University, 8 Donghunan Road, Wuhan 430072, China \\ * Correspondence: qydu@whu.edu.cn (Q.D.); malu@whu.edu.cn (L.M.); \\ Tel.: +86-27-8766-4557 (Q.D.); +86-27-6875-8815 (L.M.) \\ + Luwei Feng and Bo Ye contributed equally to this paper.
}

Received: 15 September 2017; Accepted: 27 October 2017; Published: 30 October 2017

\begin{abstract}
In recent years, research on the spatiotemporal distribution and health effects of fine particulate matter $\left(\mathrm{PM}_{2.5}\right)$ has been conducted in China. However, the limitations of different research scopes and methods have led to low comparability between regions regarding the mortality burden of $\mathrm{PM}_{2.5}$. A kriging model was used to simulate the distribution of $\mathrm{PM}_{2.5}$ in 2015 and 2016. Relative risk (RR) at a specified $\mathrm{PM}_{2.5}$ exposure concentration was estimated with an integrated exposure-response (IER) model for different causes of mortality: lung cancer (LC), ischaemic heart disease (IHD), cerebrovascular disease (stroke) and chronic obstructive pulmonary disease (COPD). The population attributable fraction (PAF) was adopted to estimate deaths attributed to $\mathrm{PM}_{2.5} .72 .02 \%$ of cities experienced decreases in $\mathrm{PM}_{2.5}$ from 2015 to 2016. Due to the overall decrease in the $\mathrm{PM}_{2.5}$ concentration, the total number of deaths decreased by approximately 10,658 per million in 336 cities, including a decrease of 1400, 1836, 6312 and 1110 caused by LC, IHD, stroke and COPD, respectively. Our results suggest that the overall $\mathrm{PM}_{2.5}$ concentration and $\mathrm{PM}_{2.5}$-related deaths exhibited decreasing trends in China, although air quality in local areas has deteriorated. To improve air pollution control strategies, regional $\mathrm{PM}_{2.5}$ concentrations and trends should be fully considered.
\end{abstract}

Keywords: $\mathrm{PM}_{2.5}$; spatiotemporal characteristics; population exposure; mortality burden; China

\section{Introduction}

Fine particulate matter $\left(\mathrm{PM}_{2.5}\right)$ is well known for its negative impacts on human health. Notably, it has contributed to 4.24 million deaths, according to the Global Burden of Disease study 2015 (GBD 2015) [1]. Exposure to $\mathrm{PM}_{2.5}$ could lead to cardiovascular [2-4] and respiratory diseases [5,6], which have been extensively investigated in a number of epidemiological cohort studies. Although the mechanisms are not fully understood, exposure to $\mathrm{PM}_{2.5}$ has been found to be linked to certain pregnancy outcomes $[7,8]$ and disorders of the nervous system. Among the diseases associated with $\mathrm{PM}_{2.5}$ concentrations, stroke, ischaemic heart disease (IHD), lung cancer (LC) and chronic obstructive 
pulmonary disease (COPD) ranked as the 1st, 2nd, 4th and 5th highest causes of death in China, as reported in GBD 2015 [1]. Diseases, and even death, can result in various economic problems. According to the World Bank, the cost of the excess deaths associated with air pollution is approximately $1.2 \%$ (using the adjusted human capital approach) or $3.8 \%$ (using the "value of a statistical life" method) of the GDP [9].

In the past several decades, China has achieved rapid economic growth, industrialization and urbanization, with annual increases in GDP of 9.7\% from 1979 to 2015, according to the Chinese Statistical Yearbook 2016, published by China Statistics Press [10]. During the same period, advances in technology and education, coupled with pollution control policies, have had positive effects on decreasing air pollution [11-14]. Still, cities in China rank among the most polluted in the world, including some international cosmopolitan cities such as Beijing [13,15] and Shanghai [16]. Notably, the North China Plain has experienced poor air conditions and persistent fog and haze [17,18]. An increasing concern over the adverse influences of particulate matter, especially $\mathrm{PM}_{2.5}$, on human health could be seen along with the promotion of health awareness among citizens. Some previous studies examined the association between $\mathrm{PM}_{2.5}$ and daily mortality in several Chinese cities, including Shanghai [19], Guangzhou [20], Xi'an [21] and Shenyang [22]. However, the cities often explored by researchers were economically advanced or heavily polluted, and low comparability existed between the results due to the various research methods adopted. The methods such as the linear model and the logarithm model have some differences, especially in estimating the air pollution burden at a high polluted level. The linear model produces a linear increase in relative risk (RR) from the lowest air pollution level to the highest (below $50 \mu \mathrm{g} / \mathrm{m}^{3}$ ). Meanwhile, the marginal increase of logarithm model is more gradual than that of the linear model at higher concentrations. What they have in common is that they both fail to cover the global range of $\mathrm{PM}_{2.5}$ exposure and will lead to a deviation at higher $\mathrm{PM}_{2.5}$ concentrations [23]. As a result, estimating the health impact of $\mathrm{PM}_{2.5}$ in all cities through a more unified and accurate approach is necessary in order for local governments to formulate relevant policies.

The Chinese government started organizing daily reports and forecasts of urban air quality in 2000 , but $\mathrm{PM}_{2.5}$ was not included in the routine monitoring items until the release of the "Ambient Air Quality Standard" (AAQS) (GB 3095-2012) in 2012. Additionally, at the end of the same year, 74 key cities published hourly $\mathrm{PM}_{2.5}$ monitoring data. In 2015, 336 prefecture-level cities adopted a new standard of air quality monitoring and began to monitor various pollutants, including $\mathrm{PM}_{2.5}$. Meanwhile, the exploration of spatial and temporal variability in $\mathrm{PM}_{2.5}$ has expanded to a national scale, as the coverage of air quality monitoring data sets has expanded and data have become readily available. The air quality monitoring network in China also provides a great opportunity for researchers to conduct $\mathrm{PM}_{2.5}$-related research on a national scale.

This study is motivated by multiple factors. It is crucial for policy designers to understand the health benefits of $\mathrm{PM}_{2.5}$ control and the health risks arising from the deterioration of air quality. In addition, though there have been some nationwide studies exploring the association between the number of deaths and exposure to $\mathrm{PM}_{2.5}$ concentrated in China, more research has focused on certain big cities. In this paper, we used hourly air quality monitoring data in 336 prefecture level cities to explore the spatial and temporal distribution of $\mathrm{PM}_{2.5}$ in China and to estimate the numbers and trends of stroke deaths, IHD deaths, LC deaths and COPD deaths over the past two years due to the impact of $\mathrm{PM}_{2.5}$ in each city. These deaths are a direct reflection of the health burden of $\mathrm{PM}_{2.5}$. Additionally, the ground-level $\mathrm{PM}_{2.5}$ data adopted in this study have covered all the cities in China and have high temporal resolutions (as they have been published hourly). 


\section{Materials and Methods}

\subsection{Materials}

\subsubsection{Ground Monitoring $\mathrm{PM}_{2.5}$ Data}

The hourly $\mathrm{PM}_{2.5}$ concentrations from January 2015 to December 2016 in 336 cities were obtained from the China National Environmental Monitoring Center (CNEMC), and spatial coverage of the data is illustrated in Figure 1. The micro oscillating balance method and the beta absorption method were used to measure $\mathrm{PM}_{2.5}$. The instruments which measured $\mathrm{PM}_{2.5}$ concentration in each site were tested by using at least 3 samplers based on HJ 618-2011, according to the regulations published by the Ministry of Environmental Protection of the People's Republic of China [24]. The CNEMC website [25] is a public website that provides air quality data free of charge, and the data are from national air quality automatic monitoring sites and were initially reviewed by the release system. In this paper, daily, monthly and yearly $\mathrm{PM}_{2.5}$ concentrations were all calculated based on hourly data. Although the source and acquisition process were credible, further filtering and correction were necessary because of some routine maintenance activities, communication failures and power outages at monitoring sites could lead to the absence of data. The data were transformed into z scores (standard scores), and data were removed when the following conditions were met: (1) less than $12 \mathrm{~h}$ of valid data were available for a day; (2) the absolute $z$ score was larger than 4; or (3) the increase from the previous value was larger than 6 [26]. After the screening and deletion processes, more than $85 \%$ of the hourly data could be used for further calculation.

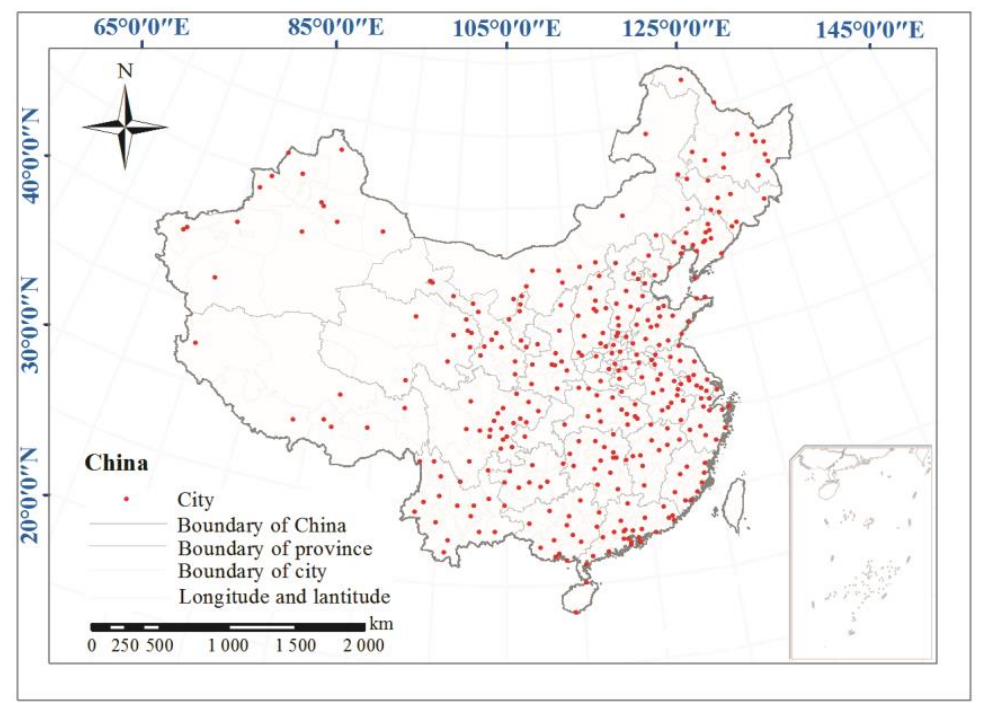

Figure 1. Locations of the 336 Chinese cities with available and sufficient data.

\subsubsection{Population and Mortality Data}

The population and deaths reported at each monitoring site were collected, summarized and combined in the China Death Monitoring Data Set. The China Death Monitoring Data Set was edited by two departments, the National Health and Family Planning Commission of the People's Republic of China and the Chinese Center for Disease Control and prevention. The data quality at each monitoring site was evaluated before data collection, and sites with serious missing reports which might affect the overall results were excluded, as described in the dataset instructions. The latest data of the number and cause of deaths were provided by the China Death Monitoring Data Set 2014. This data set included the deaths from LC (C33-C34), IHD (I20-I25), stroke (I60-I69), and COPD (J40-J44), as well as the total number of deaths in the eastern region (including Beijing, Tianjin, Hebei, Liaoning, Shanghai, Jiangsu, Zhejiang, Fujian, Shandong, Guangdong and Hainan), central region 
(including Shanxi, Jilin, Heilongjiang, Anhui, Jiangxi, and Henan) and western region (including Inner Mongolia, Guangxi, Chongqing, Sichuan, Guizhou, Yunnan, Tibet, Shaanxi, Gansu, Qinghai, Ningxia and Xinjiang) of China. Provincial population and mortality information was obtained from the provincial Statistical Bulletin of National Economic and Social Development.

\subsection{Methods}

\subsubsection{Kriging Model}

To visualize the regional profiles of $\mathrm{PM}_{2.5}$ across China, a kriging model was applied to generate a nationally continuous surface based on the $\mathrm{PM}_{2.5}$ concentrations in 336 cities. Kriging is a high-level statistical process used to generate an estimated surface based on a set of scatter points with $\mathrm{z}$ values. As a famous interpolation method, it was first used in the mineral industry and later used in a wide variety of disciplines, such as air pollution mapping [27]. Among the various versions of kriging, we employed ordinary kriging, a commonly used variant of the kriging algorithm [28,29], to construct an unbiased estimator without the requirement of a stationary mean of observed values in advance. The predictive formula of the kriging model is shown in Equation (1):

$$
\mathrm{Z}\left(\mathrm{S}_{0}\right)=\sum_{\mathrm{i}=1}^{\mathrm{N}} \lambda_{\mathrm{i}} \mathrm{Z}\left(\mathrm{S}_{\mathrm{i}}\right)
$$

where $\mathrm{Z}\left(\mathrm{S}_{0}\right)$ is the predictive value, $\mathrm{Z}\left(\mathrm{S}_{\mathrm{i}}\right)$ is the measurement at position $\mathrm{i}, \mathrm{N}$ is the number of measurements, and $\lambda_{i}$ is the unknown weight of the predictive value at position $i$. Here, weight relies on not only distance and the predictive positions of measurement points, but also on the spatial arrangement of measurement points. Therefore, the estimation of a semivariogram $\gamma(\mathrm{h})$ at a distance of $h$ is necessary to provide spatial autocorrelation information for the data set before creating predictive surfaces. To ensure that kriging predictions have positive kriging variances, it is necessary to fit a model - that is, a continuous function or curve-to the empirical semivariogram. Linear, circular, spherical, exponential and Gaussian are some models used to fit different types of phenomena [30,31]. For example, spherical model shows a progressive decrease of spatial autocorrelation until some distance, beyond which the autocorrelation is zero. The formula is shown in Equation (2):

$$
\begin{gathered}
\gamma(\mathrm{h})=\mathrm{C}_{0}+\mathrm{C}_{1}\left[\frac{3 \mathrm{~h}}{2 \mathrm{a}}-\frac{1}{2}\left(\frac{\mathrm{h}}{\mathrm{a}}\right)^{3}\right], 0 \leq \mathrm{h} \leq \mathrm{a} \\
\gamma(\mathrm{h})=\mathrm{C}_{0}+\mathrm{C}_{1}, \mathrm{~h}>\mathrm{a}
\end{gathered}
$$

where $C_{0}, C_{1}, C_{0}+C_{1}$ and a represent nugget, partial sill, sill and range respectively.

\subsubsection{Integrated Exposure-Response (IER) Model}

An increase in the $\mathrm{PM}_{2.5}$ concentration could lead to higher rates of LC, IHD, stroke and COPD. To estimate the number of premature deaths caused by $\mathrm{PM}_{2.5}$ in 2015 and 2016, we applied the IER model proposed by Burnett et al. The IER model is an effective predictor of relative risk. RR is the ratio of the probability of an event occurring in an exposed group to the probability of the event occurring in a comparable, non-exposed group. Notably, the IER model combines the RRs of ambient air pollution, second-hand tobacco smoke, household solid cooking fuel and active smoking, and yields reasonable predictions over a range of concentrations that prevail in China and other highly polluted areas. RR can be calculated using Equation (3):

$$
\begin{gathered}
\operatorname{RR}_{\operatorname{IER}(z)=1, z<z_{c f}} \\
\operatorname{RR}_{\operatorname{IER}}(z)=1+\alpha\left\{1-\exp \left[-\gamma\left(z-z_{c f}\right)^{\delta}\right]\right\}, z \geq z_{c f}
\end{gathered}
$$


where $\mathrm{z}$ is the exposure to $\mathrm{PM}_{2.5}$ and $\mathrm{z}_{\mathrm{cf}}$ is the $\mathrm{PM}_{2.5}$ concentration below which no additional risk exists. Here, we define $z_{\mathrm{cf}}$ as a uniform random variable between $5.8 \mu \mathrm{g} / \mathrm{m}^{3}$-the minimum concentration observed in the American Cancer Society Cancer Prevention II cohort [32] —and $8.8 \mu \mathrm{g} / \mathrm{m}^{3}$ — the 5th percentile value. For very large $\mathrm{z}$ values, $\mathrm{RR}_{\mathrm{IER}}$ approximates $1+\alpha$. Parameter $\delta$ is a power of $\mathrm{PM}_{2.5}$ to predict risk over a very large range of concentrations. Further, $\mathrm{RR}_{\mathrm{IER}}\left(\mathrm{z}_{\mathrm{cf}}+1\right)$ approximates $1+\alpha \gamma$. Thus, $\gamma=\left[\operatorname{RR}_{\mathrm{IER}}\left(\mathrm{z}_{\mathrm{cf}}+1\right)-1\right] /\left[\operatorname{RR}_{\mathrm{IER}}(\infty)-1\right]$ can be interpreted as the ratio of the $\mathrm{RR}$ at low-to-high exposures. $\alpha, \gamma$, and $\delta$ are unknown parameters, estimated using nonlinear regression methods according to the RR information and the variance estimates of the logarithms of RRs at different $\mathrm{PM}_{2.5}$ concentration from the available literature [33]. The detailed information about the estimates of $(\alpha, \gamma, \delta)$, and the confidence interval for $R_{\mathrm{IER}}$ can be found in the supplemental material.

\subsubsection{Estimates of Health Impacts and Mortality Due to Exposure to $\mathrm{PM}_{2.5}$}

Two assumptions used in this study should be noted before further analysis: (1) that the proportion of deaths caused by four diseases (LC, IHD, stroke and COPD) compared to total deaths was the same in 2015 and 2014 (this assumption was made because the 2015 China Death Monitoring Data Set has not been published as of the writing of this article), and (2) that city-level death rates are the same as the death rate of the associated province (this assumption was made because the death rates are unavailable for many cities).

The deaths impacts (DI) due to $\mathrm{PM}_{2.5}$ exposure in each city can be estimated using Equation (4):

$$
\mathrm{DI}_{\mathrm{i}, \mathrm{j}}=\text { Population }_{\mathrm{i}} \times \text { Mortality }_{\mathrm{i}, \mathrm{j}} \times \mathrm{PAF}_{\mathrm{i}, \mathrm{j}}
$$

where $\mathrm{DI}_{\mathrm{i}, \mathrm{j}}$ is the number of deaths due to exposure to $\mathrm{PM}_{2.5}$ for disease $\mathrm{j}$ in city $\mathrm{i}$. Population $\mathrm{i}_{\mathrm{i}}$ is the exposed population in city $i$. Mortality ${ }_{i, j}$ represents the mortality of disease $j$ in city $i . \mathrm{PAF}_{\mathrm{i}, \mathrm{j}}$ is the population attributable fraction (PAF) of the cause-specific mortality of disease $\mathrm{j}$ in city i. Specifically, PAF can be determined using Equation (5):

$$
\mathrm{PAF}_{\mathrm{i}, \mathrm{j}}=\left(\mathrm{RR}_{\mathrm{Ci}, \mathrm{j}}-1\right) / \mathrm{RR}_{\mathrm{Ci}, \mathrm{j}}
$$

where $R R_{C i, j}$ is the $R R$ of the specific mortality of disease $j$ at exposure level $C_{i}$ estimated from the IER model. Non-exposure mortality in each city can be computed based on the exposure mortality and PAF in 2015. Thus, cause-specific mortality in 2016 can easily be determined using Equation (6):

$$
\mathrm{PAF}_{\mathrm{i}, \mathrm{j}}=\left(\text { Mortality }_{\mathrm{i}, \mathrm{j}}-\text { Mortality }_{\text {non-exposure }}\right) / \text { Mortality }_{\mathrm{i}, \mathrm{j}}
$$

Then, with the cause-specific mortality and PAF in 2015 and 2016, the mortality trends associated with changes in the $\mathrm{PM}_{2.5}$ concentration per million people in each city can be obtained.

\section{Results and Discussion}

\subsection{Spatial Distribution of $P M_{2.5}$}

Figure 2 illustrates the spatial distribution of the $\mathrm{PM}_{2.5}$ concentration in 2015 and 2016 across China, estimated using the ordinary kriging model performed on the ArcGIS (version 10.3, Environmental Systems Research Institute, Redlands, CA, USA) (selection of some parameters: Spherical model used to fit semivariogram, 1000 set as output cell size and 12 points considered for the search radius). A high degree of similarity can be observed between the $\mathrm{PM}_{2.5}$ concentration distribution in 2015 and that in 2014 [34,35]. Specifically, concentrations are high on the North China Plain and low in Southwest China. However, some significant differences can be observed between the spatial patterns of $\mathrm{PM}_{2.5}$ in 2015 and 2016, including a shift in the highest $\mathrm{PM}_{2.5}$ concentration from the North China Plain to the westernmost part of China. The air quality in the North China Plain area benefited from the Air Pollution Prevention and Control (APPC) action plan initiated in 
2013 and the unified classification standard for the early warning of heavy pollution implemented in the Beijing-Tianjin-Hebei region in 2016 [36]. However, emissions caused by the increase in the number of motor vehicles and boilers, coupled with the influence of meteorological factors (increased regional sand weather, and rise of temperature and decrease of precipitation in the winter of 2015/2016) contributed to the aggravated $\mathrm{PM}_{2.5}$ pollution in the west of Xinjiang Province [37].

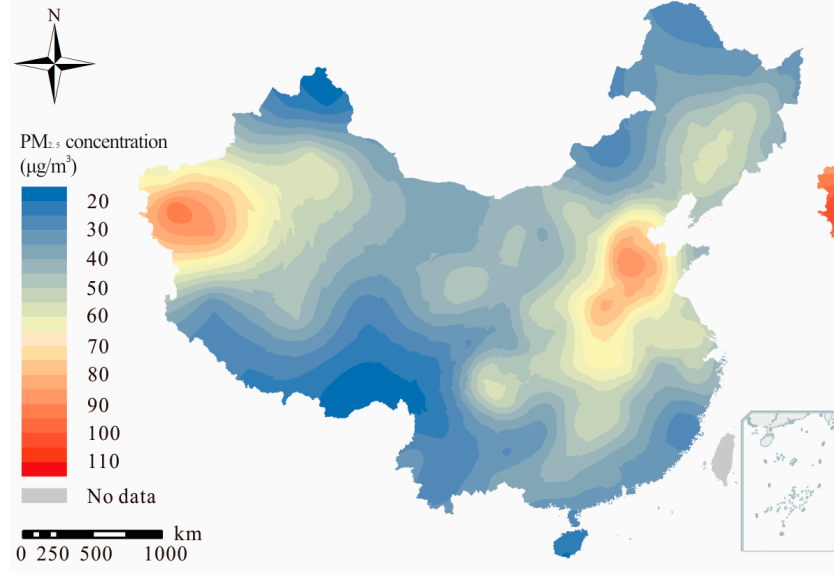

(a)

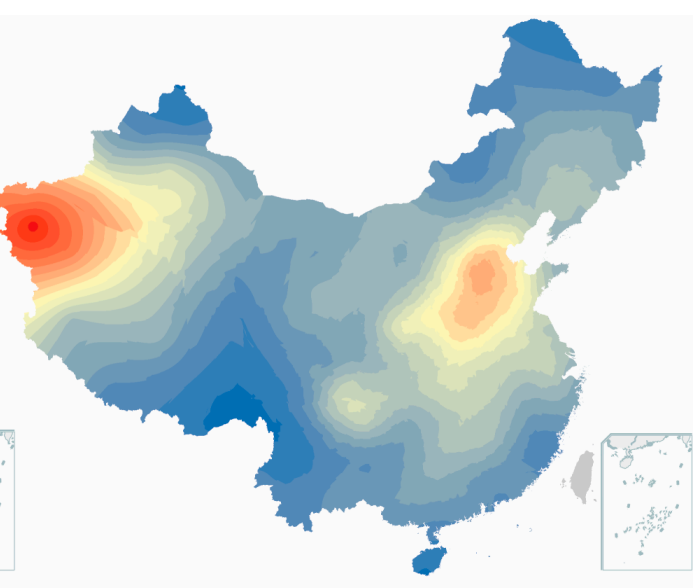

(b)

Figure 2. Spatial distribution of the annual fine particulate matter $\left(\mathrm{PM}_{2.5}\right)$ concentration in $2015(\mathbf{a})$ and 2016 (b) across China.

Overall, $72.02 \%$ of cities observed a decrease in the $\mathrm{PM}_{2.5}$ concentration from 2015 to 2016 , among which Hohhot and Xiaogan experienced the most significant decreases (of more than $20 \mu \mathrm{g} / \mathrm{m}^{3}$ ). The $\mathrm{PM}_{2.5}$ concentration in $24.40 \%$ of cities increased by less than $10 \mu \mathrm{g} / \mathrm{m}^{3}$. In addition, 7 and 5 cities exhibited an increase in $\mathrm{PM}_{2.5}$ concentrations $10-20 \mu \mathrm{g} / \mathrm{m}^{3}$ and over $20 \mu \mathrm{g} / \mathrm{m}^{3}$, respectively. At the provincial level, 23 out of 31 provinces exhibited decreased $\mathrm{PM}_{2.5}$ concentrations, and significant decreases were observed in Jilin and Hubei (Table S1). By contrast, Xinjiang exhibited the most obvious increase in its $\mathrm{PM}_{2.5}$ concentration among the remaining 8 provinces. All cities in Jilin, Hubei and Shandong exhibited declines in their $\mathrm{PM}_{2.5}$ concentrations, and $\mathrm{PM}_{2.5}$ in more than $90 \%$ of the cities in Heilongjiang, Inner Mongolia, Liaoning, Hunan and Zhejiang decreased. By contrast, the $\mathrm{PM}_{2.5}$ concentration in approximately $90.91 \%$ of the cities in Shanxi increased to some extent.

According to the WHO air quality guidelines (AQGs), an annual average concentration of $10 \mu \mathrm{g} / \mathrm{m}^{3}$ is set as the long-term guideline value for $\mathrm{PM}_{2.5}$, over which significant effects on survival are observed. Besides this guideline, three interim targets are also defined and may benefit countries in gauging progress over time in the process of reducing $\mathrm{PM}_{2.5}$ exposures. An annual mean $\mathrm{PM}_{2.5}$ concentration of $35 \mu \mathrm{g} / \mathrm{m}^{3}$ is defined as the IT- 1 level, which is associated with about a $15 \%$ higher long-term mortality risk. The IT-2 level is set at $25 \mu \mathrm{g} / \mathrm{m}^{3}$, and this level lowers the risk of premature mortality by about $6 \%$, relative to the IT- 1 level. The IT-3 level is $15 \mu \mathrm{g} / \mathrm{m}^{3}$, reducing the mortality risk by approximately $6 \%$ relative to IT- 2 level. The proportions of the hourly $\mathrm{PM}_{2.5}$ concentrations exceeding the WHO annual threshold values in 2015 and 2016 were not equally distributed at a national scale. Figure $\mathrm{S} 1$ shows the distribution of the hourly $\mathrm{PM}_{2.5}$ concentrations of all 336 cities in the ranges of $\leq 10 \mu \mathrm{g} / \mathrm{m}^{3}, 10-15 \mu \mathrm{g} / \mathrm{m}^{3}, 15-25 \mu \mathrm{g} / \mathrm{m}^{3}, 25-35 \mu \mathrm{g} / \mathrm{m}^{3}$ and $>35 \mu \mathrm{g} / \mathrm{m}^{3}$. An obvious geographical difference in the distribution of the $\mathrm{PM}_{2.5}$ concentration can be observed in Figure S1. The concentration of $\mathrm{PM}_{2.5}$ has declined in recent years, but it is still far from the WHO standard. A previous study indicated that the areal proportion of China with a $\mathrm{PM}_{2.5}$ concentration of less than $35 \mu \mathrm{g} / \mathrm{m}^{3}$ decreased from 1999 to 2011 [38]. Additionally, more than $50 \%$ of cities were in a stage of "non-attainment" in September, although September was the month when the largest number of cities exhibited minimum $\mathrm{PM}_{2.5}$ concentrations among 190 Chinese cities in 2014 [34]. Most monitoring sites exceeded the WHO standard, and only $0.38 \%, 0.41 \%$ and $12.93 \%$ of stations met the WHO IT-3, IT-2 and IT- 1 thresholds, 
respectively, in China in 2015. Only 1\% of susceptible people (of age 61 and over, or 13 and under) lived in areas with relatively safe levels of $\mathrm{PM}_{2.5}$ (less than $10 \mu \mathrm{g} / \mathrm{m}^{3}$ ) in 2010 [39], and approximately $14 \%$ (181.08 million) of people were exposed to $\mathrm{PM}_{2.5}$ concentrations lower than the WHO IT-1 threshold in 2015 [40].

\subsection{Temporal Trends of $P M_{2.5}$}

The $\mathrm{PM}_{2.5}$ concentration in 2016 was $2.27 \mu \mathrm{g} / \mathrm{m}^{3}$ lower than that of 2015 , which is consistent with the decreasing trend in $\mathrm{PM}_{2.5}$ from 2014 to 2016 reported in a previous study [41]. Winter, spring, and summer experienced decreases in the $\mathrm{PM}_{2.5}$ concentration from 2015 to 2016, especially in spring, with a $4.15 \mu \mathrm{g} / \mathrm{m}^{3}$ decline. The $\mathrm{PM}_{2.5}$ concentration exhibited clear seasonal variations and the basic trends were similar in 2015 and 2016. High concentrations in autumn and winter exhibited considerable fluctuations, while low concentrations in spring and summer exhibited moderate fluctuations, as shown in Figure 3. The seasonal variations in air pollution were consistent between years [42]. Severe air pollution occurred in winter months because of high emissions from heating and unfavorable meteorological conditions for pollution dispersion (stagnant weather and temperature inversion) [43]. Crop residue burning can also induce an evident $\mathrm{PM}_{2.5}$ increase in winter and autumn [31]. In contrast, sufficient precipitation and active atmospheric circulation led to low pollution on summer days $[34,44,45]$. The two curves illustrating the change in the $\mathrm{PM}_{2.5}$ concentration over the two years differ and display different peak and valley trends and fluctuation ranges.

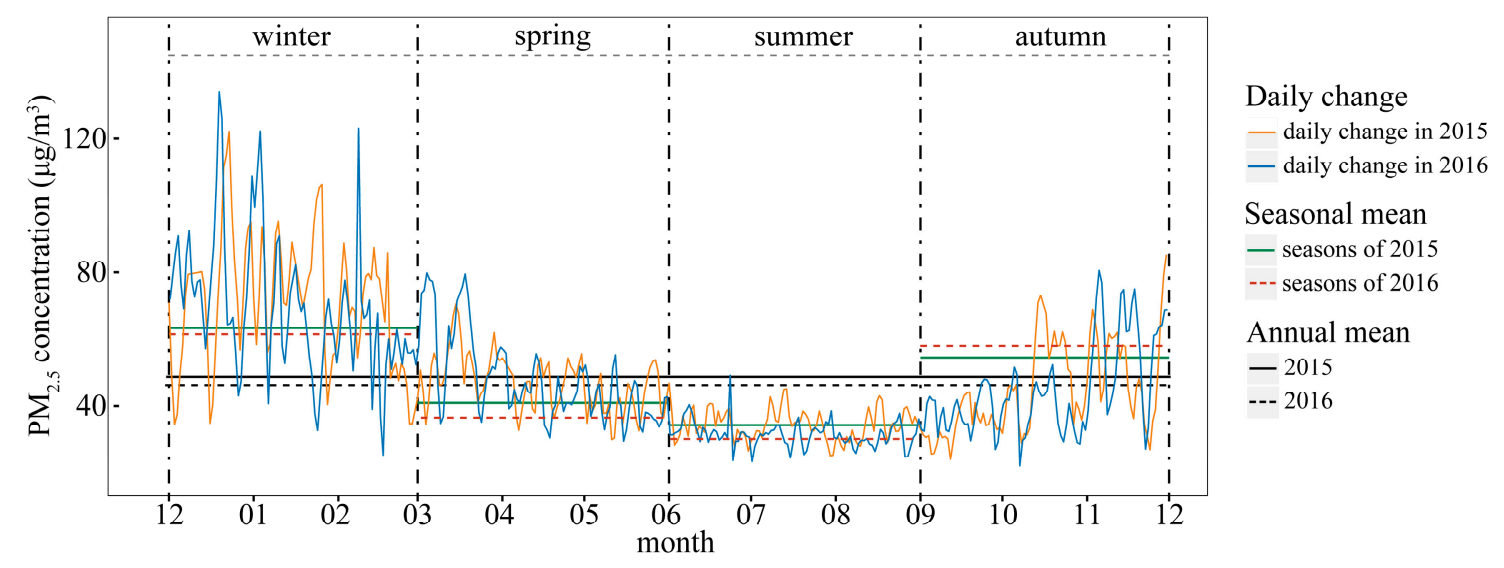

Figure 3. Variation in the $\mathrm{PM}_{2.5}$ concentration in 2015 and 2016.

Diurnal variations in the $\mathrm{PM}_{2.5}$ concentration in the four seasons in 2015 and 2016 exhibited similar trends. Notably, after midnight, the concentration gradually increased to the highest value of the day before decreasing to a minimum value and then rising again, as shown in Figure S2. However, the peak and valley times of $\mathrm{PM}_{2.5}$ concentrations over the four seasons were not entirely consistent. The maximum difference between the highest and lowest values occurred in winter, reaching $17.72 \mu \mathrm{g} / \mathrm{m}^{3}$ in both years. Meanwhile, the minimum difference occurred in summer, with a value of approximately $9.69 \mu \mathrm{g} / \mathrm{m}^{3}$ in 2015 and $8.36 \mu \mathrm{g} / \mathrm{m}^{3}$ in 2016. Similar trends in the diurnal variation of $\mathrm{PM}_{2.5}$ can be observed in some studies conducted by other researchers $[18,40,41]$. Enhanced anthropogenic activity during rush hour contributed to the morning peak in the $\mathrm{PM}_{2.5}$ concentration, which was studied through the comparison between $\mathrm{PM}_{2.5}$ diurnal changes in weekdays and weekends [46], as well as the contract between $\mathrm{PM}_{2.5}$ concentration diurnal trends in urban and rural areas [47]. Following the morning peak, the decrease in traffic pollution combined with the increase in convective movement led to the decline in the $\mathrm{PM}_{2.5}$ concentration. In the evening, traffic pollution and cooking emissions led to a gradual elevation of $\mathrm{PM}_{2.5}$ concentration and around midnight, electricity generation caused industrial pollution, increasing the $\mathrm{PM}_{2.5}$ concentration. Thus, seasonal shifts in peak and valley times can potentially be attributed to seasonal changes of residents' behaviors. 
However, not all cities exhibited diurnal variations that are consistent with the average condition of the 336 cities, which may be explained by the variety of urbanization level, sources of pollution and people's lifestyle. For example, $\mathrm{PM}_{2.5}$ concentration peaks appeared at 8:00 and 20:00 and valleys occurred at 1:00 and 15:00 in Guilin, Guangxi Province. In addition, Changde in Hunan exhibited four small peaks during a day but displayed a narrow range of fluctuation [42].

\subsection{Disease Burden of $P M_{2.5}$}

The $\mathrm{PM}_{2.5}$ concentration, $\mathrm{RR}$ and standard error were obtained from the aggregated information in the supplemental material of Burnett et al.'s paper [33] for the burdens of diseases (including LC, IHD, stroke and COPD), based on published sources. The relationship between the $\mathrm{PM}_{2.5}$ concentration and RR was calculated using the IER model, as shown in Figure 4. The curves of LC and COPD are almost straight lines, which suggest that $\mathrm{RR}$ increased uniformly as the $\mathrm{PM}_{2.5}$ concentration increased. For the curves corresponding to stroke and IHD, RR increased rapidly when the $\mathrm{PM}_{2.5}$ concentration was below $50 \mu \mathrm{g} / \mathrm{m}^{3}$ and then increased slowly. Deaths attributed to $\mathrm{PM}_{2.5}$ based on the actual populations in 31 provinces and deaths per million residents in 336 cities were calculated based on the PAF.

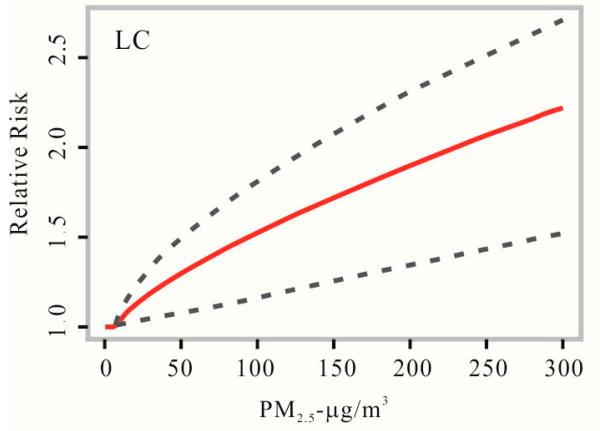

(a)

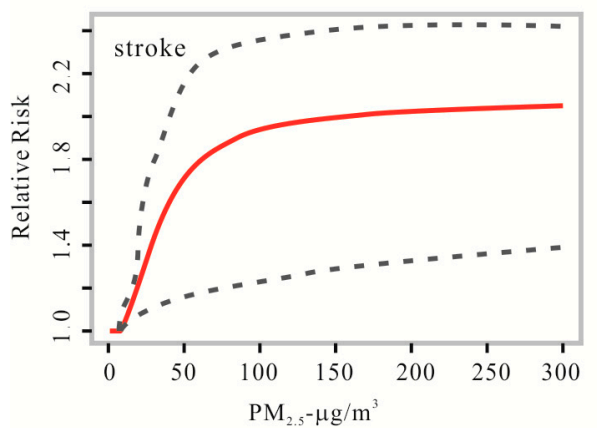

(c)

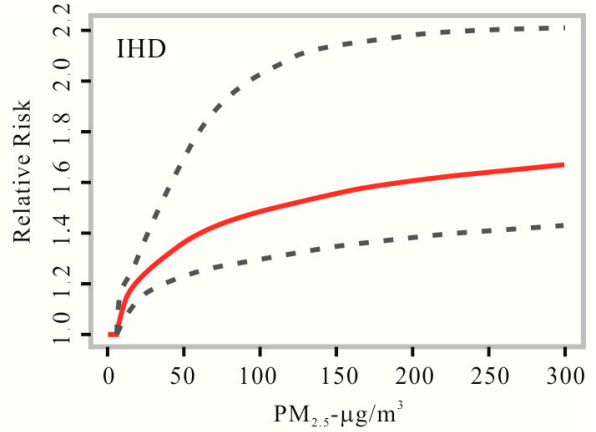

(b)

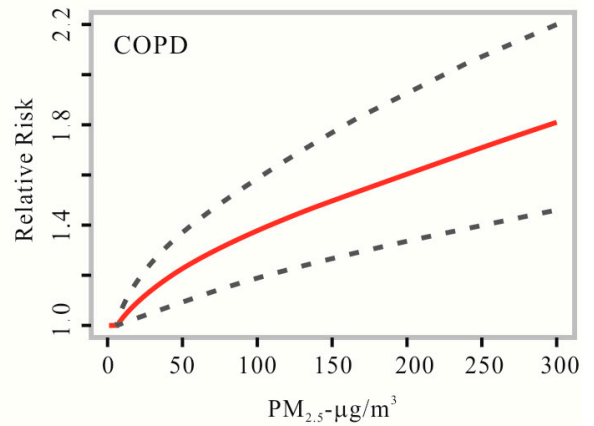

(d)

Figure 4. Relationships between the relative risk (RR) of (a) lung cancer (LC), (b) ischaemic heart disease (IHD), (c) stroke, and (d) chronic obstructive pulmonary disease (COPD) and the $\mathrm{PM}_{2.5}$ concentration predicted by the IER model. Red lines and dotted lines represent predicted values of IER model and 95\% CIs respectively.

Among 31 provinces, Henan exhibited the largest RRs for four causes of premature mortality, with values of $1.42,1.44,1.87$ and 1.31 for LC, IHD, stroke and COPD, respectively. In addition, Hainan exhibited the smallest RRs of 1.12, 1.20, 1.20 and 1.10 for LC, IHD, stroke and COPD, respectively. The change in $\mathrm{PM}_{2.5}$-related deaths in each province from 2015 to 2016 is listed in Table 1. The total number of deaths due to the four diseases was largest in Henan, at more than 130,000, while the lowest total was observed in Tibet, at less than 2000. This finding reflects an obvious difference between provinces. At the provincial level, 21 provinces experienced different declines in deaths due to changes in $\mathrm{PM}_{2.5}$. Heilongjiang, Hunan and Hubei were the top three provinces with the most 
obvious decreases of 6391, 5304 and 4705 deaths, respectively. In the remaining 10 provinces, Sichuan, Shanxi and Shaanxi exhibited the most significant increases from 2015 to 2016, with 2769, 2697 and 2553 more deaths, respectively. The decreases or increases in deaths per million residents related to $\mathrm{PM}_{2.5}$ in 336 Chinese cities were calculated, and the results are presented in Table S2 and Figure 5. At the city level, approximately $80 \%$ of cities exhibited fewer deaths due to the four diseases. For LC, IHD and COPD, the distributions of changes in deaths were similar, with approximately $70 \%$ of the cities exhibiting a decrease in deaths-ranging from $20 \%$ to $50 \%$-and $17 \%$ of cities exhibiting an increase in deaths-ranging from $0 \%$ to $20 \%$. The proportions of cities in different ranges were similar for stroke. In terms of the change in the total number of deaths due to $\mathrm{PM}_{2.5}$ from 2015 to 2016, Baoshan, Yichun and Hohhot exhibited the most obvious declines among the 231 cities with fewer deaths, while 23 cities remained unchanged. The remaining 82 cities exhibited more deaths, with Qiannan, Chizhou and Xianyang experiencing the three highest increases.

Our study indicated that approximately 1,126,000 deaths were caused by $\mathrm{PM}_{2.5}$ in 2015 across China. This total is slightly larger than the value estimated by GBD $2015(1,108,000)$ [48]. Moreover, our estimate decreased to approximately 1,092,000 in 2016 due to the overall decline in the $\mathrm{PM}_{2.5}$ concentration. Notably, the numbers of deaths due to LC, IHD, stroke and COPD caused by $\mathrm{PM}_{2.5}$ totalled 130,000, 284,000, 592,000 and 120,000, respectively, in 2015 and 124,000, 278,000, 573,000 and 117,000 , respectively, in 2016. Our estimates are comparable with those of previous studies. These studies found that premature deaths in China caused by $\mathrm{PM}_{2.5}$ totaled 807,000 in 2004, 1,250,000 in 2012 [49], 1,367,000 in 2013 [50], and 1,600,000 in 2014 [51]. In 2015, the number of deaths per million people attributed to $\mathrm{PM}_{2.5}$ was 813 in China. This total was more than four times that in the United States and Japan. Additionally, China accounted for approximately a quarter of global deaths $(4,241,000)$, which suggests that air pollution remains a serious problem in China. However, according to our research, air pollution in China improved significantly from 2015 to 2016, based on the fact that $72.02 \%$ of the cities exhibited varying decreases in their $\mathrm{PM}_{2.5}$ concentrations, and $68.75 \%$ of the cities exhibited decreases in mortality attributed to $\mathrm{PM}_{2.5}$. Improvements in air quality in China indicate that the policies and measures taken by the government have achieved initial success. To ensure the continuity and effectiveness of air pollution control, it is necessary to reduce heating, cooking and agricultural emissions [52] and adjust regional policies according to changes in $\mathrm{PM}_{2.5}$ concentration. 


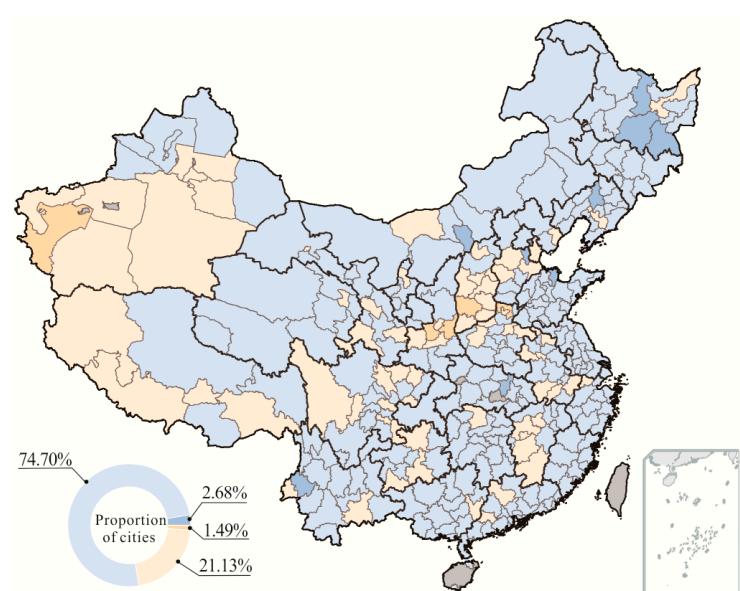

(a)

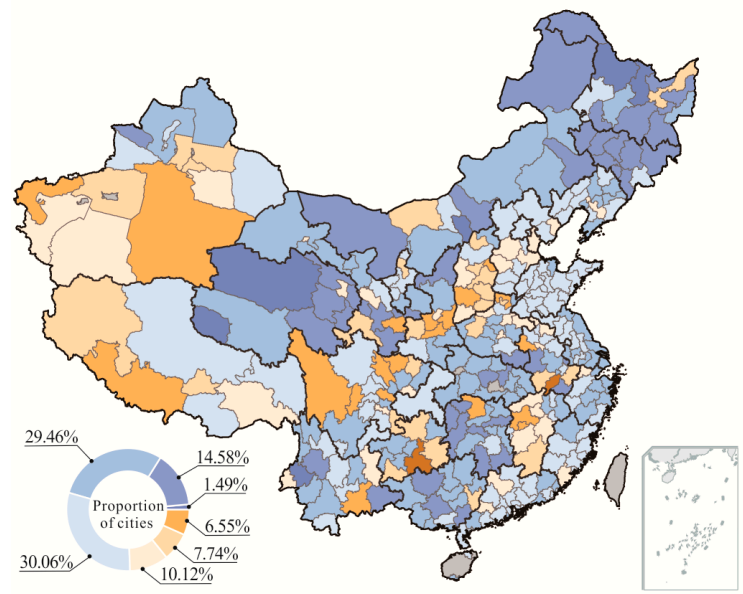

(c)

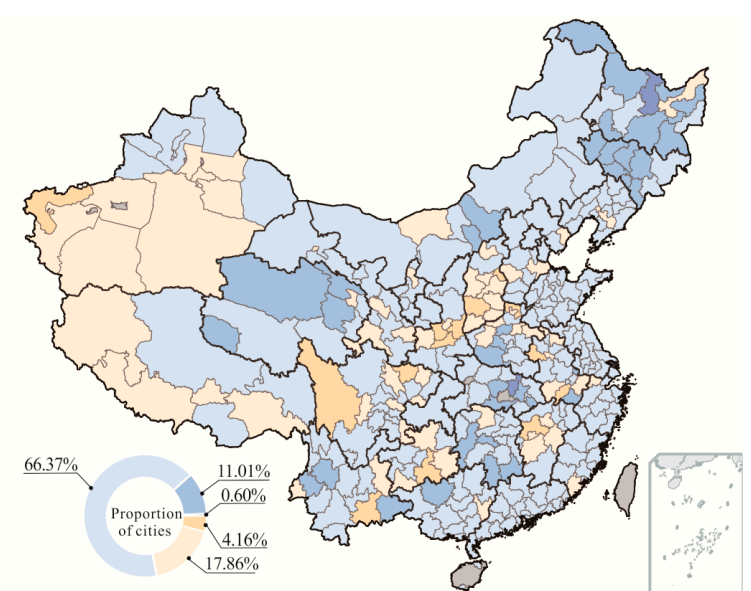

(b)

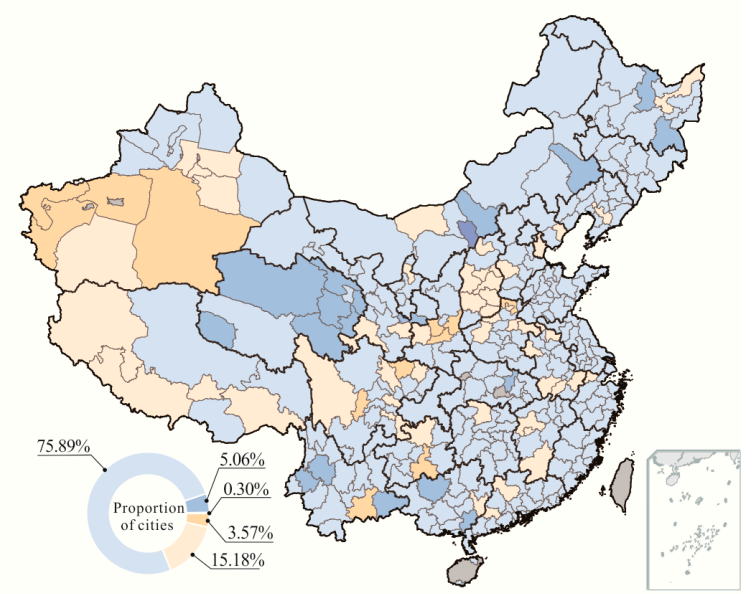

(d)

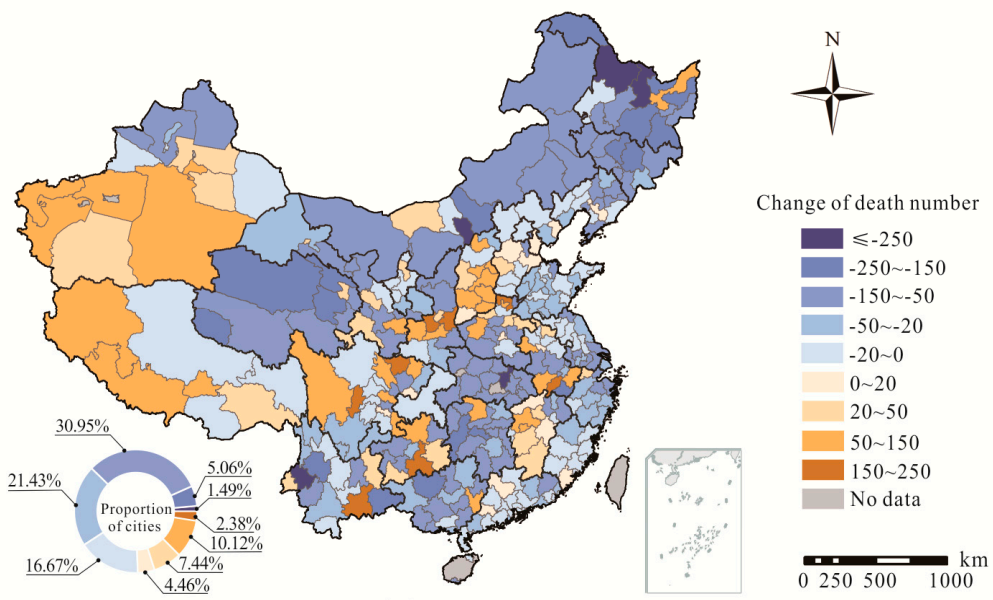

(e)

Figure 5. Distributions of changes in (a) LC deaths, (b) IHD deaths, (c) stroke deaths, (d) COPD deaths and (e) total deaths from 2015 to 2016. 
Table 1. Changes in deaths due to exposure to $\mathrm{PM}_{2.5}$ at the provincial level.

\begin{tabular}{|c|c|c|c|c|c|c|c|c|c|c|c|c|c|c|c|c|c|}
\hline \multirow{2}{*}{ Province } & \multirow{2}{*}{\multicolumn{2}{|c|}{$\begin{array}{c}\text { Population }\left(\times 10^{6}\right) \\
2015-2016\end{array}$}} & \multicolumn{5}{|c|}{ Attributable Deaths in $2015\left(\times 10^{3}\right)$} & \multicolumn{5}{|c|}{ Attributable Deaths in $2016\left(x^{3}\right)$} & \multicolumn{5}{|c|}{ Change from 2015 to $2016^{a}$} \\
\hline & & & LC & IHD & Stroke & COPD & SUM & LC & IHD & Stroke & COPD & SUM & LC & IHD & Stroke & COPD & SUM \\
\hline Heilongiiang & 38.12 & 37.99 & 3.18 & 11.20 & 21.59 & 3.21 & 39.17 & 2.64 & 10.11 & 17.36 & 2.66 & 32.78 & -539 & -1084 & -4225 & -543 & -6391 \\
\hline Hunan & 67.83 & 68.22 & 7.19 & 23.07 & 46.41 & 7.27 & 83.94 & 6.54 & 21.95 & 43.48 & 6.68 & 78.64 & -659 & -1122 & -2930 & -594 & -5304 \\
\hline Hubei & 58.52 & 58.85 & 6.02 & 17.89 & 36.08 & 6.06 & 66.06 & 5.24 & 17.10 & 33.60 & 5.42 & 61.35 & -784 & -797 & -2481 & -643 & -4705 \\
\hline Jilin & 27.53 & 27.33 & 2.35 & 7.55 & 15.18 & 2.38 & 27.47 & 1.96 & 6.68 & 13.01 & 2.05 & 23.70 & -394 & -866 & -2177 & -326 & -3762 \\
\hline Guangxi & 47.96 & 48.38 & 3.24 & 8.77 & 22.96 & 6.59 & 41.56 & 2.87 & 8.30 & 20.81 & 5.94 & 37.92 & -363 & -476 & -2155 & -642 & -3636 \\
\hline Jiangsu & 79.76 & 79.99 & 10.40 & 12.86 & 23.95 & 4.03 & 51.23 & 9.48 & 12.21 & 22.46 & 3.72 & 47.87 & -919 & -643 & -1493 & -312 & -3366 \\
\hline Guangdong & 108.49 & 109.99 & 6.08 & 9.01 & 15.34 & 2.32 & 32.74 & 5.58 & 8.52 & 13.68 & 2.21 & 29.99 & -503 & -484 & -1654 & -115 & -2756 \\
\hline Yunnan & 47.42 & 47.71 & 2.57 & 7.78 & 18.09 & 5.28 & 33.71 & 2.30 & 7.52 & 16.33 & 4.93 & 31.08 & -272 & -254 & -1757 & -347 & -2630 \\
\hline Shandong & 98.47 & 99.47 & 14.27 & 16.44 & 29.82 & 5.45 & 65.98 & 13.36 & 15.84 & 29.07 & 5.13 & 63.40 & -911 & -606 & -749 & -312 & -2578 \\
\hline Inner Mongolia & 25.11 & 25.20 & 1.47 & 4.07 & 10.51 & 2.98 & 19.03 & 1.29 & 3.71 & 8.97 & 2.68 & 16.65 & -171 & -356 & -1544 & -304 & -2376 \\
\hline Liaoning & 43.82 & 43.78 & 4.98 & 6.37 & 11.87 & 1.94 & 25.16 & 4.64 & 6.18 & 10.87 & 1.77 & 23.46 & -337 & -183 & -1001 & -171 & -1691 \\
\hline Henan & 94.80 & 95.32 & 12.92 & 37.49 & 73.49 & 13.22 & 137.11 & 12.68 & 36.84 & 73.05 & 12.86 & 135.43 & -238 & -649 & -443 & -356 & -1686 \\
\hline Zhejiang & 55.39 & 55.90 & 4.98 & 6.58 & 11.89 & 1.90 & 25.35 & 4.67 & 6.26 & 11.09 & 1.73 & 23.75 & -313 & -319 & -800 & -165 & -1597 \\
\hline Shanghai & 24.15 & 24.20 & 2.17 & 2.75 & 5.07 & 0.82 & 10.81 & 1.89 & 2.53 & 4.53 & 0.72 & 9.67 & -276 & -219 & -548 & -106 & -1148 \\
\hline Gansu & 26.00 & 26.10 & 1.75 & 4.75 & 12.45 & 3.57 & 22.53 & 1.62 & 4.62 & 11.86 & 3.40 & 21.50 & -134 & -130 & -586 & -174 & -1024 \\
\hline Hebei & 74.25 & 74.70 & 9.34 & 10.76 & 19.52 & 3.56 & 43.18 & 9.17 & 10.58 & 19.18 & 3.47 & 42.39 & -172 & -186 & -338 & -98 & -795 \\
\hline Qinghai & 5.88 & 5.93 & 0.41 & 1.11 & 2.89 & 0.81 & 5.21 & 0.35 & 1.01 & 2.53 & 0.73 & 4.62 & -60 & -92 & -357 & -79 & -588 \\
\hline Fujian & 38.39 & 38.74 & 2.67 & 4.02 & 6.45 & 1.03 & 14.18 & 2.54 & 4.06 & 6.18 & 0.97 & 13.75 & -125 & 37 & -275 & -65 & -429 \\
\hline Anhui & 61.44 & 61.96 & 5.78 & 18.09 & 36.68 & 5.90 & 66.46 & 5.65 & 18.25 & 36.49 & 5.70 & 66.09 & -133 & 153 & -190 & -198 & -369 \\
\hline Hainan & 9.11 & 9.17 & 0.44 & 0.76 & 0.89 & 0.16 & 2.25 & 0.37 & 0.73 & 0.72 & 0.15 & 1.96 & -70 & -33 & -174 & -17 & -294 \\
\hline Beijing & 21.71 & 21.73 & 2.33 & 2.69 & 4.88 & 0.89 & 10.79 & 2.28 & 2.69 & 4.83 & 0.86 & 10.66 & -54 & 3 & -51 & -29 & -132 \\
\hline Ningxia & 6.68 & 6.75 & 0.36 & 0.95 & 2.53 & 0.71 & 4.55 & 0.36 & 0.96 & 2.55 & 0.72 & 4.60 & 4 & 10 & 27 & 7 & 48 \\
\hline Tibet & 3.24 & 3.31 & 0.13 & 0.41 & 0.86 & 0.25 & 1.64 & 0.13 & 0.41 & 0.93 & 0.27 & 1.75 & 3 & 8 & 71 & 26 & 107 \\
\hline Guizhou & 35.30 & 35.55 & 2.23 & 6.82 & 16.29 & 4.64 & 29.97 & 2.24 & 6.87 & 16.41 & 4.67 & 30.19 & 16 & 49 & 118 & 33 & 217 \\
\hline Tianjin & 15.47 & 15.62 & 1.82 & 2.14 & 3.86 & 0.68 & 8.50 & 1.88 & 2.16 & 4.00 & 0.71 & 8.75 & 65 & 21 & 132 & 31 & 249 \\
\hline Chongqing & 30.17 & 30.48 & 2.82 & 7.19 & 19.20 & 5.67 & 34.88 & 2.85 & 7.26 & 19.40 & 5.73 & 35.24 & 30 & 76 & 203 & 60 & 369 \\
\hline Xinjiang & 23.60 & 23.98 & 1.38 & 3.53 & 9.42 & 2.78 & 17.11 & 1.59 & 3.78 & 10.36 & 3.20 & 18.92 & 203 & 251 & 939 & 414 & 1807 \\
\hline Jiangxi & 45.66 & 45.92 & 3.84 & 12.98 & 25.51 & 3.80 & 46.13 & 4.01 & 13.45 & 26.92 & 4.02 & 48.41 & 171 & 471 & 1411 & 223 & 2277 \\
\hline Shaanxi & 37.93 & 38.13 & 3.02 & 7.74 & 20.75 & 6.01 & 37.51 & 3.23 & 8.21 & 22.03 & 6.59 & 40.06 & 218 & 472 & 1283 & 580 & 2553 \\
\hline Shanxi & 36.64 & 36.82 & 3.23 & 10.10 & 20.48 & 3.29 & 37.10 & 3.55 & 10.70 & 21.97 & 3.59 & 39.80 & 320 & 597 & 1489 & 292 & 2697 \\
\hline Sichuan & 82.04 & 82.62 & 6.64 & 17.72 & 47.06 & 13.27 & 84.69 & 6.94 & 18.37 & 48.12 & 14.03 & 87.46 & 295 & 650 & 1062 & 762 & 2769 \\
\hline SUM & 1371 & 1380 & 130 & 284 & 592 & 120 & 1126 & 124 & 278 & 573 & 117 & 1092 & -6102 & -5701 & $-19,193$ & -3168 & $-34,164$ \\
\hline
\end{tabular}




\subsection{Strengths and Limitations}

Few studies have explored the $\mathrm{PM}_{2.5}$-related mortality burden using local health data (including population and mortality data) in China, and most studies have focused on key cities or regions instead of the entire country. Due to the adoption of different algorithms, low comparability exists between these studies. Our study used hourly, ground-level $\mathrm{PM}_{2.5}$ monitoring data, population data and mortality data to estimate the deaths in China caused by $\mathrm{PM}_{2.5}$ using the IER model and PAF. This approach overcomes the limitations of small-scale research. Moreover, these findings can be used to inform people regarding the health impacts of $\mathrm{PM}_{2.5}$ pollution and provide guidance for regional policy design.

However, some limitations and uncertainties exist in our study. The evaluation was based on city-level $\mathrm{PM}_{2.5}$ concentrations calculated by averaging the data at all sites, which is the common method used to report daily air quality to the public. However, the uneven distribution of monitoring stations, including more in urban areas and less in suburban and rural areas, makes a simple averaging method less accurate than more complex methods [40]. In addition, the assumptions proposed before further calculations were sources of uncertainties as well, but the assumptions were inevitable due to the unavailability of certain data. Furthermore, the IER model was adopted to estimate the relationships between $\mathrm{PM}_{2.5}$ and the RRs of four diseases in our study. However, a highly accurate exposure-response model based completely on Chinese cohort studies should be developed in the future, even though the IER model provides reasonable predictions in China and other heavily polluted areas [49].

\section{Conclusions}

The spatial distributions, temporal trends and health burdens of $\mathrm{PM}_{2.5}$ in 336 Chinese cities in 2015 and 2016 were evaluated based on hourly $\mathrm{PM}_{2.5}$ concentrations. The annual average $\mathrm{PM}_{2.5}$ concentration decreased by $2.27 \mu \mathrm{g} / \mathrm{m}^{3}$, from $48.33 \mu \mathrm{g} / \mathrm{m}^{3}$ in 2015 to $46.06 \mu \mathrm{g} / \mathrm{m}^{3}$ in 2016 . Additionally, the region with the highest $\mathrm{PM}_{2.5}$ concentration shifted from the North China Plain in 2015 to western Xinjiang Province in 2016. Although the $\mathrm{PM}_{2.5}$ levels in China are still far above the WHO standard, 70.02\% of Chinese cities exhibited decreases in $\mathrm{PM}_{2.5}$ concentrations between 2015 and 2016. Moreover, 34,164 deaths (including 6102 LC deaths, 5701 IHD deaths, 19,193 stroke deaths and 3168 COPD deaths) were avoided due to the overall decrease in the $\mathrm{PM}_{2.5}$ concentration in China from 2015 to 2016. New findings in this paper could enhance public awareness regarding the health risks caused by $\mathrm{PM}_{2.5}$. We urge governments in Chinese provinces and cities to take effective measures to curb air pollution. In addition, to avoid a rebound in $\mathrm{PM}_{2.5}$ pollution, sustainable strategies and joint actions among cities should be considered.

Supplementary Materials: The following are available online at www.mdpi.com/1660-4601/14/11/1321/s1, Estimates of $(\alpha, \gamma, \delta)$, Estimates of confidence interval for $R_{\text {IER }}$, Figure S1: Proportion distributions of hourly $\mathrm{PM}_{2.5}$ concentrations in 336 cities. Figure S2: Diurnal variation of $\mathrm{PM}_{2.5}$ concentration in four seasons over 2015 and 2016. Table S1: Change of $\mathrm{PM}_{2.5}$ concentration in provinces from 2015 to 2016. and Table S2: Changes in deaths caused by fluctuations of $\mathrm{PM}_{2.5}$ concentrations from 2015 to 2016 in 336 Chinese cities.

Acknowledgments: This study is supported by the National Key Research and Development Programme of China (2016 YFC 0803106) and the National Natural Science Foundation of China (Project No. 41371427).

Author Contributions: Luwei Feng, Bo Ye, Fu Ren, Huan Feng, Shichun Huang, Xiaotong Zhang, Yunquan Zhang, Qingyun Du and Lu Ma worked collectively. Specifically, Qingyun Du, Lu Ma and Fu Ren developed the original idea for the study and conducted the organization of the content. Huan Feng, Shichun Huang, Xiaotong Zhang and Yunquan Zhang collected the data and established the dataset. Luwei Feng and Bo Ye conducted the experiments, performed the discussion of the results and drafted the article. All authors read and approved the final manuscript.

Conflicts of Interest: The authors declare no conflict of interest. 


\section{References}

1. Forouzanfar, M.H.; Afshin, A.; Alexander, L.T.; Anderson, H.R.; Bhutta, Z.A.; Biryukov, S.; Brauer, M.; Burnett, R.; Cercy, K.; Charlson, F.J.; et al. Global, regional, and national comparative risk assessment of 79 behavioural, environmental and occupational, and metabolic risks or clusters of risks, 1990-2015: A systematic analysis for the global burden of disease study 2015. Lancet 2016, 388, 1659-1724. [CrossRef]

2. Pope, C.A.; Burnett, R.T.; Thun, M.J.; Calle, E.E.; Krewski, D.; Ito, K.; Thurston, G.D. Lung cancer, cardiopulmonary mortality, and long-term exposure to fine particulate air pollution. JAMA J. Am. Med. Assoc. 2002, 287, 1132-1141. [CrossRef]

3. Haley, V.B.; Talbot, T.O.; Felton, H.D. Surveillance of the short-term impact of fine particle air pollution on cardiovascular disease hospitalizations in new york state. Environ. Health 2009, 8, 42. [CrossRef] [PubMed]

4. Chen, H.; Burnett, R.T.; Kwong, J.C.; Villeneuve, P.J.; Goldberg, M.S.; Brook, R.D.; van Donkelaar, A.; Jerrett, M.; Martin, R.V.; Kopp, A.; et al. Spatial association between ambient fine particulate matter and incident hypertension. Circulation 2014, 129, 562-569. [CrossRef] [PubMed]

5. Da Silva, A.M.C.D.; Mattos, I.E.; Freitas, S.R.; Longo, K.M.; Hacon, S.S. Particulate matter $\left(\mathrm{PM}_{2.5}\right)$ of biomass burning emissions and respiratory diseases in the south of the Brazilian Amazon. Rev. Bras. Epidemiol. 2010, 13, 337-351.

6. Dominici, F.; Peng, R.D.; Bell, M.L.; Pham, L.; McDermott, A.; Zeger, S.L.; Samet, J.M. Fine particulate air pollution and hospital admission for cardiovascular and respiratory diseases. JAMA J. Am. Med. Assoc. 2006, 295, 1127-1134. [CrossRef] [PubMed]

7. Stieb, D.M.; Chen, L.; Beckerman, B.S.; Jerrett, M.; Crouse, D.L.; Omariba, D.W.R.; Peters, P.A.; van Donkelaar, A.; Martin, R.V.; Burnett, R.T.; et al. Associations of pregnancy outcomes and PM 2.5 in a national Canadian study. Environ. Health Perspect. 2016, 124, 243-249. [CrossRef] [PubMed]

8. Tanaka, S. Environmental regulations on air pollution in China and their impact on infant mortality. J. Health Econ. 2015, 42, 90-103. [CrossRef] [PubMed]

9. Mundial, B. World Development Report 2007; World Bank: Washington, DC, USA, 2006.

10. National Bureau of Statistics of the People's Republic of China. Available online: http:/ /www.stats.gov.cn/ (accessed on 10 January 2017).

11. Wang, Z.; Pan, L.; Li, Y.; Zhang, D.; Ma, J.; Sun, F.; Xu, W.; Wang, X. Assessment of air quality benefits from the national pollution control policy of thermal power plants in China: A numerical simulation. Atmos. Environ. 2015, 106, 288-304. [CrossRef]

12. Xue, B.; Mitchell, B.; Geng, Y.; Ren, W.; Müller, K.; Ma, Z.; Oliveira, J.A.P.D.; Fujita, T.; Tobias, M. A review on China's pollutant emissions reduction assessment. Ecol. Ind. 2014, 38, 272-278. [CrossRef]

13. Chen, Y.; Schleicher, N.; Fricker, M.; Cen, K.; Liu, X.L.; Kaminski, U.; Yu, Y.; Wu, X.F.; Norra, S. Long-term variation of black carbon and $\mathrm{PM}_{2.5}$ in Beijing, China with respect to meteorological conditions and governmental measures. Environ. Pollut. 2016, 212, 269-278. [CrossRef] [PubMed]

14. Yuan, Y.; Liu, S.; Castro, R.; Pan, X. PM 2.5 monitoring and mitigation in the cities of China. Environ. Sci. Technol. 2012, 46, 3627. [CrossRef] [PubMed]

15. Zhang, A.; Qi, Q.; Jiang, L.; Zhou, F.; Wang, J. Population exposure to $\mathrm{PM}_{2.5}$ in the urban area of Beijing. PLoS ONE 2013, 8, e63486. [CrossRef] [PubMed]

16. Wang, H.L.; Qiao, L.P.; Lou, S.R.; Zhou, M.; Ding, A.J.; Huang, H.Y.; Chen, J.M.; Wang, Q.; Tao, S.; Chen, C.H.; et al. Chemical composition of $\mathrm{PM}_{2.5}$ and meteorological impact among three years in urban Shanghai, China. J. Clean. Prod. 2016, 112, 1302-1311. [CrossRef]

17. Ding, Y.; Liu, Y. Analysis of long-term variations of fog and haze in China in recent 50 years and their relations with atmospheric humidity. Sci. China Earth Sci. 2014, 57, 36-46. [CrossRef]

18. Hu, J.; Wang, Y.; Ying, Q.; Zhang, H. Spatial and temporal variability of $\mathrm{PM}_{2.5}$ and $\mathrm{PM}_{10}$ over the North China Plain and the Yangtze River Delta, China. Atmos. Environ. 2014, 95, 598-609. [CrossRef]

19. Kan, H.; London, S.J.; Chen, G.; Zhang, Y.; Song, G.; Zhao, N.; Jiang, L.; Chen, B. Differentiating the effects of fine and coarse particles on daily mortality in Shanghai, China. Environ. Int. 2007, 33, 376-384. [CrossRef] [PubMed]

20. Yang, C.; Peng, X.; Huang, W.; Chen, R.; Xu, Z.; Chen, B.; Kan, H. A time-stratified case-crossover study of fine particulate matter air pollution and mortality in Guangzhou, China. Int. Arch. Occup. Environ. Health 2012, 85, 579-585. [CrossRef] [PubMed] 
21. Cao, J.; Xu, H.; Xu, Q.; Chen, B.; Kan, H. Fine particulate matter constituents and cardiopulmonary mortality in a heavily polluted Chinese city. Environ. Health Perspect. 2012, 120, 373-378. [CrossRef] [PubMed]

22. Ma, Y.; Chen, R.; Pan, G.; Xu, X.; Song, W.; Chen, B.; Kan, H. Fine particulate air pollution and daily mortality in Shenyang, China. Sci. Total Environ. 2011, 409, 2473-2477. [CrossRef] [PubMed]

23. Ezzati, M.; Lopez, A.D.; Rodgers, A.; Murray, C.J.L. Comparative quantification of health risks. Can. Nurse 2005, 1, 1 .

24. Ministry of Environmental Protection of the People's Republic of China. Available online: http://kjs.mep. gov.cn/hjbhbz/bzwb/jcffbz/201109/t20110914_217272.shtml (accessed on 2 August 2017).

25. China National Environmental Monitoring Center. Available online: http://www.cnemc.cn/ (accessed on 10 January 2017).

26. He, J.; Gong, S.; Yu, Y.; Yu, L.; Wu, L.; Mao, H.; Song, C.; Zhao, S.; Liu, H.; Li, X.; et al. Air pollution characteristics and their relation to meteorological conditions during 2014-2015 in major Chinese cities. Environ. Pollut. 2017, 223, 484-496. [CrossRef] [PubMed]

27. Chang, K.-T. Introduction to Geographic Information Systems; McGraw-Hill: New York, NY, USA, 2006; pp. 429-444.

28. Furrer, R.; Genton, M.G.; Nychka, D. Covariance tapering for interpolation of large spatial datasets. J. Comput. Graph. Stat. 2006, 15, 502-523. [CrossRef]

29. Guo, M.; Wang, X.F.; Li, J.; Yi, K.P.; Zhong, G.S.; Wang, H.M.; Tani, H. Spatial distribution of greenhouse gas concentrations in arid and semi-arid regions: A case study in East Asia. J. Arid Environ. 2013, 91, 119-128. [CrossRef]

30. Schneider, K.; Huisman, J.A.; Breuer, L.; Frede, H.G. Ambiguous effects of grazing intensity on surface soil moisture: A geostatistical case study from a steppe environment in Inner Mongolia, PR China. J. Arid Environ. 2008, 72, 1305-1319. [CrossRef]

31. Yin, S.; Wang, X.; Xiao, Y.; Tani, H.; Zhong, G.; Sun, Z. Study on spatial distribution of crop residue burning and $\mathrm{PM}_{2.5}$ change in China. Environ. Pollut. 2017, 220, 204. [CrossRef] [PubMed]

32. Krewski, D.; Jerrett, M.; Burnett, R.T.; Ma, R.; Hughes, E.; Shi, Y.; Turner, M.C.; Rd, P.C.; Thurston, G.; Calle, E.E. Extended follow-up and spatial analysis of the American Cancer Society study linking particulate air pollution and mortality. Res. Rep. 2009, 140, 5.

33. Burnett, R.T.; Pope, C.A., III; Ezzati, M.; Olives, C.; Lim, S.S.; Mehta, S.; Shin, H.H.; Singh, G.; Hubbell, B.; Brauer, M.; et al. An integrated risk function for estimating the global burden of disease attributable to ambient fine particulate matter exposure. Environ. Health Perspect. 2014, 122, 397-403. [CrossRef] [PubMed]

34. Zhang, H.; Wang, Z.; Zhang, W. Exploring spatiotemporal patterns of $\mathrm{PM}_{2.5}$ in China based on ground-level observations for 190 cities. Environ. Pollut. 2016, 216, 559-567. [CrossRef] [PubMed]

35. Chen, L.; Shi, M.; Gao, S.; Li, S.; Mao, J.; Zhang, H.; Sun, Y.; Bai, Z.; Wang, Z. Assessment of population exposure to $\mathrm{PM}_{2.5}$ for mortality in China and its public health benefit based on benmap. Environ. Pollut. 2017, 221, 311-317. [CrossRef] [PubMed]

36. Fang, D.; Wang, Q.-G.; Li, H.; Yu, Y.; Lu, Y.; Qian, X. Mortality effects assessment of ambient $\mathrm{PM}_{2.5}$ pollution in the 74 leading cities of China. Sci. Total Environ. 2016, 569, 1545-1552. [CrossRef] [PubMed]

37. Chen, Z.; Xie, X.; Cai, J.; Chen, D.; Gao, B.; He, B.; Cheng, N.; Xu, B. Understanding meteorological influences on $\mathrm{PM}_{2.5}$ concentrations across China: A temporal and spatial perspective. Atmos. Chem. Phys. 2017, 1-30. [CrossRef]

38. Peng, J.; Chen, S.; Lu, H.; Liu, Y.; Wu, J. Spatiotemporal patterns of remotely sensed $\mathrm{PM}_{2.5}$ concentration in China from 1999 to 2011. Remote Sens. Environ. 2016, 174, 109-121. [CrossRef]

39. Han, L.; Zhou, W.; Li, W. City as a major source area of fine particulate $\left(\mathrm{PM}_{2.5}\right)$ in China. Environ. Pollut. 2015, 206, 183-187. [CrossRef] [PubMed]

40. Guo, H.; Cheng, T.; Gu, X.; Wang, Y.; Chen, H.; Bao, F.; Shi, S.; Xu, B.; Wang, W.; Zuo, X.; et al. Assessment of $\mathrm{PM}_{2.5}$ concentrations and exposure throughout China using ground observations. Sci. Total Environ. 2017, 601, 1024. [CrossRef] [PubMed]

41. Song, C.; Wu, L.; Xie, Y.; He, J.; Chen, X.; Wang, T.; Lin, Y.; Jin, T.; Wang, A.; Liu, Y.; et al. Air pollution in China: Status and spatiotemporal variations. Environ. Pollut. 2017, 227, 334-347. [CrossRef] [PubMed]

42. Wang, Y.Q.; Zhang, X.Y.; Sun, J.Y.; Zhang, X.C.; Che, H.Z.; Li, Y. Spatial and temporal variations of the concentrations of $\mathrm{PM}_{10}, \mathrm{PM}_{2.5}$ and $\mathrm{PM}_{1}$ in China. Atmos. Chem. Phys. 2015, 15, 13585-13598. [CrossRef] 
43. Wang, S.; Zhou, C.; Wang, Z.; Feng, K.; Hubacek, K. The characteristics and drivers of fine particulate matter $\left(\mathrm{PM}_{2.5}\right)$ distribution in China. J. Clean. Prod. 2017, 142, 1800-1809. [CrossRef]

44. Wang, P.; Cao, J.J.; Shen, Z.X.; Han, Y.M.; Lee, S.C.; Huang, Y.; Zhu, C.S.; Wang, Q.Y.; Xu, H.M.; Huang, R.J. Spatial and seasonal variations of $\mathrm{PM}_{2.5}$ mass and species during 2010 in Xi'an, China. Sci. Total Environ. 2015, 508, 477-487. [CrossRef] [PubMed]

45. Yao, L.; Lu, N. Spatiotemporal distribution and short-term trends of particulate matter concentration over China, 2006-2010. Environ. Sci. Pollut. Res. Int. 2014, 21, 9665. [CrossRef] [PubMed]

46. Zhao, X.; Zhang, X.; Xu, X.; Xu, J.; Meng, W.; Pu, W. Seasonal and diurnal variations of ambient $\mathrm{PM}_{2.5}$ concentration in urban and rural environments in Beijing. Atmos. Environ. 2009, 43, 2893-2900. [CrossRef]

47. Chen, W.; Tang, H.; Zhao, H. Diurnal, weekly and monthly spatial variations of air pollutants and air quality of Beijing. Atmos. Environ. 2015, 119, 21-34. [CrossRef]

48. Cohen, A.J.; Brauer, M.; Burnett, R.; Anderson, H.R.; Frostad, J.; Estep, K.; Balakrishnan, K.; Brunekreef, B.; Dandona, L.; Dandona, R. Estimates and 25-year trends of the global burden of disease attributable to ambient air pollution: An analysis of data from the global burden of diseases study 2015. Lancet 2017, 389, 1907. [CrossRef]

49. Liu, M.; Huang, Y.; Ma, Z.; Jin, Z.; Liu, X.; Wang, H.; Liu, Y.; Wang, J.; Jantunen, M.; Bi, J.; et al. Spatial and temporal trends in the mortality burden of air pollution in China: 2004-2012. Environ. Int. 2017, 98, 75-81. [CrossRef] [PubMed]

50. Liu, J.; Han, Y.; Tang, X.; Zhu, J.; Zhu, T. Estimating adult mortality attributable to $\mathrm{PM}_{2.5}$ exposure in China with assimilated $\mathrm{PM}_{2.5}$ concentrations based on a ground monitoring network. Sci. Total Environ. 2016, 568, 1253. [CrossRef] [PubMed]

51. Rohde, R.A.; Muller, R.A. Air pollution in China: Mapping of concentrations and sources. PLoS ONE 2015, 10, e0135749. [CrossRef] [PubMed]

52. Lelieveld, J.; Evans, J.S.; Fnais, M.; Giannadaki, D.; Pozzer, A. The contribution of outdoor air pollution sources to premature mortality on a global scale. Nature 2015, 525, 367-371. [CrossRef] [PubMed]

(C) 2017 by the authors. Licensee MDPI, Basel, Switzerland. This article is an open access article distributed under the terms and conditions of the Creative Commons Attribution (CC BY) license (http:/ / creativecommons.org/licenses/by/4.0/). 